\title{
Analysis of SMA Hybrid Composite Structures in MSC.Nastran and ABAQUS
}

\author{
Travis L. Turner* \\ NASA Langley Research Center \\ Aero and Structural Acoustics Branch \\ Hampton, VA 23681-2199 \\ Hemant D. Patel \\ MSC.Software Corporation \\ 2 MacArthur Place \\ Santa Ana, CA 92707
}

Number of Pages: 39

Number of Figures: 11

Number of Tables: 3

*ALL CORRESPONDENCE SHOULD BE DIRECTED TO:

Travis L. Turner

NASA Langley Research Center

Aero and Structural Acoustics Branch

Building 1208, Room 110, Mail Stop 463

Hampton, VA 23681-2199

Phone: 757-864-3598

Fax: 757-864-8823

Email: t.l.turner@,nasa.gov 


\begin{abstract}
A thermoelastic constitutive model for shape memory alloy (SMA) actuators and SMA hybrid composite (SMAHC) structures was recently implemented in the commercial finite element codes MSC.Nastran and ABAQUS. The model may be easily implemented in any code that has the capability for analysis of laminated composite structures with temperature dependent material properties. The model is also relatively easy to use and requires input of only fundamental engineering properties. A brief description of the model is presented, followed by discussion of implementation and usage in the commercial codes. Results are presented from static and dynamic analysis of SMAHC beams of two types; a beam clamped at each end and a cantilever beam. Nonlinear static (post-buckling) and random response analyses are demonstrated for the first specimen. Static deflection (shape) control is demonstrated for the cantilever beam. Approaches for modeling SMAHC material systems with embedded SMA in ribbon and small round wire product forms are demonstrated and compared. The results from the commercial codes are compared to those from a research code as validation of the commercial implementations; excellent correlation is achieved in all cases.
\end{abstract}

\title{
KEYWORDS
}

Shape memory alloys, Nitinol, SMA hybrid composites, MSC.Nastran, ABAQUS, finite element analysis, post-buckling control, vibration control, shape control, deflection control

\section{INTRODUCTION}

There has been growing interest in adaptive materials and structures in recent years. Structures that adapt to their environment or have the ability to change configurations have been of particular 
interest. Shape memory alloys (SMA) have enormous potential for such applications. Their energy density is generally considered as the highest of known actuators, smart materials-based or conventional, so efficient actuation concepts may be possible. The interaction of temperature and stress on the transformation behavior of SMA materials can be used to exploit phenomena such as thermally induced shape memory, pseudoelasticity, as well as combinations of these effects. Significant progress has been made in the areas of SMA materials characterization, constitutive modeling, and integration into applications. However, structural concept development and component design have been stymied by the lack of an analytical tool in a general purpose structural analysis environment. Many structural concepts involving SMA materials have been developed by trial and error and/or using excessively simplified modeling approaches.

There are various phenomenological and micromechanics-based constitutive models for SMA materials that are currently in use by various research groups. ${ }^{1-4}$ Although these models are very comprehensive in capturing the complex behavior of SMA materials, they are difficult to implement in commercial structural analysis codes and are difficult to use in practice. Thus, none of these models are in wide use, particularly by general structural analysts. An engineering model for SMA materials was recently developed based upon nonlinear thermoelasticity and definition of an effective coefficient of thermal expansion (ECTE). ${ }^{5}$ The ECTE model has the advantages of being relatively simple to use, readily implemented in commercial codes, and requiring input of only fundamental engineering properties. The ECTE model does, however, have a more restrictive range of application than the phenomenological/micromechanics-based models. Thus, it is envisioned that the ECTE model may be the model of choice for detailed design when appropriate and may be used 
in conjunction with more a comprehensive model for analyses of increasing fidelity when the case demands.

It is desirable in many applications to integrate SMA actuators into a structure, e.g., to achieve maximum space or weight efficiency, distributed or spatially varying actuation, autonomous response to environmental effects, minimum system complexity, etc. Previous studies have proposed special finite elements for modeling SMA materials according to various constitutive models, particularly the phenomenological/micromechanics-based models. These elements then provide the functionality of the actuator, separate from elements modeling the bulk of the structure. This approach is most effective when there are few actuators that are geometrically distinct from the distributed structure. This approach is inefficient, however, and intractable for practical structural analysis when there are many actuators, particularly when they are distributed within a host composite structure. This is especially true for cases involving SMA actuators of small size, like wire-type configurations. It is for these reasons that means for modeling SMAHC materials and formulating SMAHC elements is deemed necessary. The latter SMAHC modeling approach affords the ability to model an enormous number of material configurations efficiently, as long as the effective composite properties can be constructed from the constituents. The impetus for development of the ECTE model was the need to model SMAHC materials, so it is particularly suited to such modeling requirements.

The concept of embedding SMA actuators in a composite structure was introduced by Rogers and Robershaw. ${ }^{6}$ Several subsequent research efforts have investigated SMAHC laminates for a variety of applications. $^{7-11}$ The ECTE model has been used previously in a research code to analyze the 
static and dynamic response of beam and plate structures. ${ }^{5,12,13}$ It is the objective of this study to demonstrate SMAHC structural analysis using the ECTE model within the framework of commercial finite element codes. The thermally induced shape memory effect will be the focus of this work in application to structural thermoelastic, vibration, and shape control. A brief description of the modeling approach will be followed by discussion of implementation and use of the model in the commercial codes MSC.Nastran and ABAQUS. The commercial implementations of the ECTE model will be validated in comparison to a research code for the analysis cases of post-buckling, random response, and shape control of SMAHC beams. Extensive additional detail is available on the actual analysis input files and solution procedures in the companion document in reference 14 and electronic versions of all input files are available at the URL http://stabserv.larc.nasa.gov.

\section{MODEL FORMULATION}

The salient features of the ECTE constitutive model for SMA and SMAHC materials are described in this section. A more detailed description can be found elsewhere. ${ }^{5}$ There are various composite material types, structural fabrication techniques, and embedding strategies to integrate SMA actuators within a composite structure, e.g., between layers, within layers, etc. Likewise, there are many micromechanical models for evaluating the effective composite properties and resulting constitutive equations for such hybrid composites. The case considered here is that of a laminated composite composed of unidirectional pre-impregnated (pre-preg) layers with SMA actuators embedded within the laminae. A representative volume element from an individual SMAHC lamina, with principal material coordinates 1 and 2, is shown schematically in Figure 1 . This example is used for simplicity of illustration and it is understood that a similar approach could be used to model different composite materials, embedding strategies, and structure types. 
The thermoelastic constitutive relations in principal material coordinates for a thin orthotropic lamina under conditions of plane stress can be shown to have the following form

$$
\left\{\begin{array}{c}
\sigma_{1} \\
\sigma_{2} \\
\tau_{12}
\end{array}\right\}=\left[\begin{array}{ccc}
Q_{11} & Q_{12} & 0 \\
Q_{12} & Q_{22} & 0 \\
0 & 0 & Q_{66}
\end{array}\right]\left\{\left\{\begin{array}{c}
\varepsilon_{1} \\
\varepsilon_{2} \\
\gamma_{12}
\end{array}\right\}-\int_{T_{o}}^{T}\left\{\begin{array}{c}
\alpha_{1}(\tau) \\
\alpha_{2}(\tau) \\
0
\end{array}\right\} d \tau\right)
$$

where $[Q]$ is the reduced stiffness matrix, $\{\varepsilon\}$ is the total strain vector, and $\{\alpha\}$ is the vector of CTEs. The reduced stiffness terms are related to the effective engineering properties through the following equations.

$$
Q_{11}=\frac{E_{1}}{1-v_{12} v_{21}} \quad Q_{12}=\frac{v_{12} E_{2}}{1-v_{12} v_{21}} \quad Q_{22}=\frac{E_{2}}{1-v_{12} v_{21}} \quad Q_{66}=G_{12}
$$

Estimates of the effective engineering properties for the lamina in Figure 1 must be determined in order to make use of these constitutive relations. A mechanics of materials approach can be used as follows to develop the effective properties for such a SMAHC material.

The most fundamental feature of the ECTE model is the axial constitutive relation for a SMA actuator, in which the non-mechanical (i.e., thermal and transformation) strain is represented by effective thermal strain:

$$
\sigma_{1 a}(T)=E_{a}(T)\left[\varepsilon_{1}-\int_{T_{o}}^{T} \alpha_{1 a}(\tau) d \tau\right]
$$

where $E_{a}(T)$ is the Young's modulus of the SMA material, $\varepsilon_{1}$ is the total axial strain, $\alpha_{1 a}$ is the effective coefficient of thermal expansion, and the subscript $a$ indicates that the quantity is specific to the actuator material. It can be seen in Equation (3) that the ECTE model is intended to model thermally induced transformation phenomena, as opposed to stress induced (pseudoelasticity), which 
is the restriction mentioned previously. It can be shown that the thermal strain in Equation (3) is governed by the usual thermoelastic effects at temperatures below the austenite start temperature $\left(T<A_{s}\right)$ and is related to the recovery stress $\left(\sigma_{r}\right)$ and modulus $\left(E_{a}\right)$ at higher temperatures $\left(T \geq A_{s}\right):$

$$
\sigma_{r}(T)=-E_{a}(T) \int_{T_{o}}^{T} \alpha_{1 a}(\tau) d \tau \quad \text { or } \quad \int_{T_{o}}^{T} \alpha_{1 a}(\tau) d \tau=-\sigma_{r}(T) / E_{a}(T)
$$

This expression implies that measurement of the fundamental engineering properties ( $\alpha_{1 a}$ for $T<A_{s}, \sigma_{r}$ and $E_{a}$ for $T \geq A_{s}$ ) from experiments approximating the intended use condition (e.g., prestrain level and constraint) is all that is required to quantify the model. For example, an actuator under stiff constraint and restricted to small prestrain recovery in service would be well represented by measurements of blocked recovery stress. A similar constitutive expression can be written for the actuator in the transverse direction:

$$
\sigma_{2 a}(T)=E_{a}(T)\left[\varepsilon_{2}-\int_{T_{o}}^{T} \alpha_{2 a}(\tau) d \tau\right]
$$

where $\alpha_{2 a}$ is not related to recovery stress, but is still nonlinear due to differing martensitic and austenitic properties. Note that it has been assumed that the Young's modulus for the SMA is directionally independent. The analogous expressions for the composite matrix material, denoted by the subscript $m$, follow directly.

$$
\sigma_{1 m}=E_{1 m}(T)\left[\varepsilon_{1}-\int_{T_{o}}^{T} \alpha_{1 m}(\tau) d \tau\right] \quad \text { and } \quad \sigma_{2 m}=E_{2 m}(T)\left[\varepsilon_{2}-\int_{T_{o}}^{T} \alpha_{2 m}(\tau) d \tau\right]
$$

It can be shown that one form for the effective properties of a SMAHC lamina can be constructed from these constituent relations as follows. 


$$
\begin{gathered}
E_{1}=E_{a} v_{a}+E_{1 m} v_{m} \quad E_{2}=\frac{E_{a} E_{2 m}}{E_{a} v_{m}+E_{2 m} v_{a}} \quad v_{12}=v_{a} v_{a}+v_{12 m} v_{m} \quad G_{12}=\frac{G_{a} G_{12 m}}{G_{a} v_{m}+G_{12 m} v_{a}} \\
\int_{T_{o}}^{T} \alpha_{1}(\tau) d \tau=\frac{E_{a} v_{a} \int_{T_{o}}^{T} \alpha_{1 a}(\tau) d \tau+E_{1 m} v_{m} \int_{T_{o}}^{T} \alpha_{1 m}(\tau) d \tau}{E_{a} v_{a}+E_{1 m} v_{m}} \quad \int_{T_{o}}^{T} \alpha_{2}(\tau) d \tau=\int_{T_{o}}^{T}\left[\alpha_{2 a}(\tau) v_{a}+\alpha_{2 m}(\tau) v_{m}\right] d \tau
\end{gathered}
$$

These effective engineering properties can be used in conjunction with Equations (1) and (2) to define the thermoelastic characteristics of a SMAHC lamina.

Note that the ECTE model is consistent with classical thermoelasticity, so the model can be readily implemented in any finite element code that has the capability for analyzing laminated composite materials with temperature dependent material properties. It is envisioned that a similar approach might be possible for incorporation of a phenomenological or micromechanics-based 1-D constitutive model for the SMA in a SMAHC material model by replacing Equation (3) with the corresponding constitutive and kinetic relations.

\section{COMMERCIAL CODE IMPLEMENTATION}

One approach for deriving the constitutive relations governing the thermoelastic properties of a SMAHC lamina was shown in the previous section. Attention will now turn to methods for implementing material models of this type using the commercial pre-/post-processor MSC.Patran and generating the data structure necessary to perform various types of analyses on SMAHC structures within the framework of the commercial finite element codes MSC.Nastran and ABAQUS.

\subsection{MSC.Patran}


Note in Equations (7) that the volume fraction of SMA for a given SMAHC layer can range from $0 \%$ to $100 \%$. This allows for a large variety of material systems and material system modeling approaches. For example, consider the case of a SMAHC laminate with SMA ribbon embedded within or between specific laminae. Furthermore, let the actuator cross-section aspect ratio be large; thickness on the order of the lamina thickness and width on the order of typical finite element (e.g., plate or shell element) dimensions. A typical finite element cross section with this material system type is shown schematically in Figure 2a, which indicates that individual finite elements may consist of $100 \%$ SMA and/or $100 \%$ host composite matrix layers. Note that unrealistically few layers are shown for clarity of illustration. This type of SMAHC element requires only the distinct properties of the constituent materials to define the properties of the individual layers in a particular finite element and will be referred to as the mon element (or laminate) type, indicative of the monolithic SMA inclusion within a layer. Evaluation of element properties with a material system of this type can be accomplished in MSC.Patran by defining 2-D orthotropic materials to represent the SMA and composite matrix material separately. Orthotropic engineering properties are typically known or measured for a particular composite matrix material. The full complement of orthotropic engineering properties for the SMA material can be constructed from measurements of Young's modulus $E_{a}$ and recovery stress $\sigma_{r}$ by assuming that the Young's modulus and Poisson's ratio are directionally independent, the shear modulus is related to the Young's modulus through the typical isotropic relation $G=E / 2(1+v)$, the axial CTE is determined from the thermal strain in Equation (4), and the transverse CTE varies from martensitic to austenitic values. Finally, Classical Lamination Theory can be used to develop the SMAHC laminate stiffness coefficients, thermal forces, and thermal moments. 
Alternatively, a similar structural functionality and performance could be achieved with SMA actuators in the form of round wire with a diameter on the order of the lamina thickness, which suggests several actuators to a typical element width. A schematic of a finite element cross section with a material system of this type is shown in Figure $2 b$, where again relatively few layers are shown for clarity. It can be seen that individual finite elements may consist of all SMAHC layers with varying orientations and SMA content, combinations of traditional and SMAHC layers, etc. Thus, the material model for individual layers in a finite element of this type requires properties for mixtures of the constituents, defined by relations like those in Equations (7), and will be referred to as the mix element (or laminate) type, indicative of the mixture of SMA and host within a layer. In this case, evaluation of element properties can be accomplished in MSC.Patran by defining 3-D orthotropic materials representing the SMA and composite matrix material, each with equivalent mechanical properties in the two transverse directions. The constituent materials can then be combined to form a SMAHC material by the Rule-of-Mixtures approach. Lamination sequences of traditional composite and/or SMAHC laminae can be modeled through Classical Lamination Theory to develop the corresponding laminate stiffness coefficients, thermal forces, and thermal moments.

While MSC.Patran supports output of temperature dependent material property data for isotropic and anisotropic materials, it does not for orthotropic materials. Thus, modeling strategies for an anisotropic SMAHC material may be plausible for MSC.Patran output. The present study is primarily concerned with laminated SMAHC materials, which are composed of orthotropic layers. MSC.Patran will produce the laminate definition information (PCOMP bulk data entries in MSC.Nastran and *SHELL SECTION options in ABAQUS) and the temperature independent material property data for the individual laminae (MATi bulk data entries in MSC.Nastran and 
combinations of temperature independent versions of the

*MATERIAL/*ELASTIC/*EXPANSION/etc. options in ABAQUS) for both laminate types (mon and mix) described above. However, MSC.Patran will not produce the required temperature dependent material property data (MATTi and TABLEMi bulk data entries in MSC.Nastran and appropriate combinations of temperature dependent versions of the

*MATERIAL/*ELASTIC/*EXPANSION/etc. options in ABAQUS) for either laminate type. This limitation is not particularly consequential for elements of the mon laminate type, layers alternating between $100 \%$ SMA and $100 \%$ host composite, because a single tabulated data set for each constituent is all that is required. However, some additional effort is required for elements of the mix laminate type, where any given layer may consist of mixtures of SMA and host composite. In this case, a new tabulated dataset must be created from the constituent properties, by using Equations (7), for every material combination employed. The analysis input file must be hand altered, for either laminate type, to incorporate the appropriate temperature dependent material properties. Of course, this limitation might be removed in some other pre-processor that is unknown to the authors.

\subsection{MSC.Nastran}

The capability for analyzing laminated composite materials with temperature dependent material properties was recently added to MSC.Nastran. A brief description of this capability is given here, but further detail can be found in the MSC.Nastran Version 2005 Release Notes and Quick Reference Guide. This capability is available for QUAD4 and TRIA3 h-element types and is implemented for SOL 106, Nonlinear Static (NLSTATIC) solution procedure. Other response characteristics of SMAHC structures can be determined by a RESTART from any particular 
increment in a nonlinear static solution sequence. This will be described in more detail in later sections.

Two new parameters have been introduced to allow user specification of options involved in analysis of laminated composites with temperature dependent material properties. The parameter COMPMATT indicates the intent for analysis of laminated composites with temperature dependent properties and the parameter EPSILONT indicates the form of the thermal expansion property data. The form for specification of these parameters is as follows: PARAM,COMPMATT,YES (Default NO) and PARAM, EPSILONT,INTEGRAL (Default SECANT). Setting the parameter COMPMATT to YES allows PCOMP bulk data entries, which define the composite material laminate, to reference temperature dependent material properties in TABLEMi bulk data entries through corresponding MATTi $(i=1,2,8)$ and $\operatorname{MATi}(i=1,2,8)$ bulk data entries. The default value for the parameter EPSILONT causes MSC.Nastran to expect the secant form for CTE data in the TABLEMi bulk data entries and thermal strain is calculated according to the equation

$$
\varepsilon(T)=\alpha(T)\left(T-T_{\text {ref }}\right)-\alpha\left(T_{i}\right)\left(T_{i}-T_{\text {ref }}\right)
$$

where the subscripts $i$ and ref indicate initial and reference quantities, respectively. In the event that the load temperature $T$ is not equal to a tabulated value, $\alpha(T)$ is estimated by linear interpolation within the tabulated data. A value of INTEGRAL for the parameter EPSILONT indicates that the CTE data is in tangent form and the thermal strain should be calculated as the integral of the interpolated tangent CTE. Thus, the thermal strain developed over the temperature change $T_{1} \rightarrow T_{2}$ within the tabulated data interval $\left(\alpha_{i}, T_{i}\right)$ and $\left(\alpha_{j}, T_{j}\right)$ is evaluated as 


$$
\int_{T_{1}}^{T_{2}} \alpha(T) d T=\left(\frac{T_{2}-T_{1}}{T_{j}-T_{i}}\right)\left[\alpha_{j}\left(\frac{T_{2}+T_{1}}{2}-T_{i}\right)+\alpha_{i}\left(T_{j}-\frac{T_{2}+T_{1}}{2}\right)\right]
$$

and the total thermal strain is the sum of integrals over each interval from the initial to the load temperature. Note that the thermal strain over the entire interval above yields

$$
\int_{T_{i}}^{T_{j}} \alpha(T) d T=\frac{1}{2}\left(\alpha_{j}+\alpha_{i}\right)\left(T_{j}-T_{i}\right)
$$

In general, the integral approach has greater accuracy with increasing temperature interval size.

The user also has the option of specifying thermal strain directly. This is indicated in the bulk data file by assigning a negative table identification number (TID) to the TABLEMi material property table for the corresponding thermal expansion data. Of course, the same negative TID must also appear in the MATTi bulk data entry referring to the temperature dependent thermal strain data. This capability may be convenient in many cases where thermal strain is known, which is particularly useful for the ECTE model because thermal strain in the actuator's axial direction is known from Equation (4) for $T \geq A_{s}$. In this case, temperature difference evaluation of thermal strain, i.e, by the secant or integral approach, would be necessary only if analysis were required at temperatures less than $\mathrm{A}_{\mathrm{s}}$.

\subsection{ABAQUS}

ABAQUS is also capable of modeling laminated composite materials with temperature dependent material properties. This capability is available for many element types and solution procedures, so the user is referred to the ABAQUS User's and Reference Manuals. A large variety of solution combinations can be achieved by making use of restart capabilities with the *RESTART option 
and/or multiple analysis steps (*STEP option) within a single analysis input file. The *SHELL SECTION, COMPOSITE option is used to describe the material and orientation stacking sequence, which refers to corresponding *MATERIAL options. *ELASTIC, *EXPANSION, and *DENSITY options are then associated with each *MATERIAL option to fully prescribe the temperature dependent material properties. ABAQUS accepts thermal expansion data in terms of secant CTE values, but not in terms of tangent CTE values. ABAQUS also accepts input of thermal strain data by employing the USER parameter on the *EXPANSION option and defining the user subroutine UEXPAN, but this capability is not explored in this study.

\section{EXAMPLE PROBLEMS}

The commercial implementations of the ECTE model will now be demonstrated and validated through comparison with a research code for two relatively simple SMAHC structures. The cases to be considered include a beam clamped at both ends and a cantilever beam. Both mon and mix laminate types will be considered in the subsequent analyses of static and dynamic structural response.

\subsection{Clamped SMAHC Beam}

Consider a beam with a length and width of $45.72 \times 2.54 \mathrm{~cm}(18 \times 1$ inches $)$ and clamped boundary conditions at both ends. The lamination stacking sequence is $(45 / 0 /-45 / 90)_{2 s}$ with SMA ribbon material replacing a width of $1.143 \mathrm{~cm}(0.45$ inches $)$ of the $0^{\circ}$ glass-epoxy layers about the beam centerline, bounded by $0.6985 \mathrm{~cm}$ ( $0.275 \mathrm{inch})$ wide strips of glass-epoxy on either side. The thickness of each glass-epoxy layer is $0.012383 \mathrm{~cm}(0.004875$ inches $)$ and that for the SMA is $0.01524 \mathrm{~cm}$ (0.006 inches). The motivation for this particular geometry and material system is from 
a previous experimental validation study of the ECTE model as implemented in a research code. ${ }^{12}$ The finite element mesh used to model the beam specimen consists of $36 \times 4$ rectangular elements with two element widths modeling the SMA inclusion and one element width modeling each of the glass-epoxy strips along the outer edges of the beam. A graphical representation of the beam specimen and finite element mesh is shown in Figure 3. QUAD4 quadrilateral shell elements were used in MSC.Nastran, S4 quadrilateral shell elements were used in ABAQUS, and rectangular plate elements ${ }^{15}$ were used in the research code. Note that a mon laminate type modeling approach is used in this case, which results in two element types in the finite element model; one SMAHC and one glass-epoxy. The two element types have differing overall thicknesses, $0.198 \mathrm{~cm}(0.078$ inches $)$ for the glass-epoxy and $0.210 \mathrm{~cm}(0.0825$ inches $)$ for the $\mathrm{SMAHC}$, but the same mid-plane. The temperature dependent material properties for the two constituents (Nitinol and glass-epoxy) are given in Table 1 and Table 2, where the thermal expansion data is given in secant CTE form.

The physical conditions that are to be numerically simulated for this specimen involve imposing a uniformly distributed thermal load of $121.1^{\circ} \mathrm{C}\left(250^{\circ} \mathrm{F}\right)$ in the presence of the clamped boundary conditions and subjecting the beam to random out-of-plane inertial load. The inertial load is characterized by a $0.25 \mathrm{~g}$ RMS acceleration uniformly distributed over a bandwidth of $0-400 \mathrm{~Hz}$, i.e., band-limited white noise with a spectral level of $150.51\left(\mathrm{~cm} / \mathrm{s}^{2}\right)^{2} / \mathrm{Hz}\left(23.33\left(\mathrm{in} / \mathrm{s}^{2}\right)^{2} / \mathrm{Hz}\right)$. It is clear that the combination of thermal loads and immovable in-plane boundaries presents the opportunity for thermoelastic instability and large thermal post-buckling deflections. Typical numerical approaches for nonlinear static solutions involving stability require some seeding of the solution by an initial deflection to prevent numerical ill conditioning. This initial deflection can be constructed in many ways including weighted combinations of buckling eigenvectors, geometric imperfections, 
and other static deflections due to real or fictitious loads. The approach taken here is that of introducing a static gravity load of $1 \mathrm{~g}\left(9.81 \mathrm{~m} / \mathrm{s}^{2}, 386.4 \mathrm{in} / \mathrm{s}^{2}\right)$, normal to the plane of the beam, in a separate static analysis and using the resulting deflections as geometric imperfections.

The required solutions were achieved within the framework of MSC.Nastran by performing a nonlinear static solution (SOL 106) with a uniform thermal load increasing from ambient temperature to $121.1^{\circ} \mathrm{C}\left(250^{\circ} \mathrm{F}\right)$. The geometric imperfections (gravity deflections) were introduced into the nonlinear static solution by perturbing the coordinates (i.e., $x+u, y+v, z+w)$ of the GRID bulk data entries defining the nodal locations. Linear random analyses were performed, subsequent to the nonlinear static solution, using a modal approach incorporating the first 10 modes, a critical damping ratio of $0.5 \%$ for all modes, and a frequency resolution of $0.25 \mathrm{~Hz}$ at four temperatures; $23.9^{\circ} \mathrm{C}\left(75^{\circ} \mathrm{F}\right), 65.6^{\circ} \mathrm{C}\left(150^{\circ} \mathrm{F}\right), 93.3^{\circ} \mathrm{C}\left(200^{\circ} \mathrm{F}\right)$, and $121.1^{\circ} \mathrm{C}\left(250^{\circ} \mathrm{F}\right)$. Linear random analysis was accomplished as a variant of frequency response analysis (SOL 111) with the definition of the RANDPS bulk data entry that referred to a frequency dependent spectral load given by a TABRND1 bulk data entry. The imperfections were again introduced into the MSC.Nastran reference temperature, random input file by perturbing the nodal coordinates. Linear random analysis at elevated temperature was accomplished by using a RESTART statement to reuse the database from the previous nonlinear static analysis and by specifying the specific thermal load increment number with the parameter NMLOOP, i.e., with the bulk data entry PARAM,NMLOOP,\#. Thus, the geometric imperfections and thermoelastic equilibrium state are implicitly included in the elevated temperature random analyses because of the restart from the nonlinear static solution. 
A similar analysis sequence was achieved by a slightly different approach in ABAQUS. A single analysis input file was created and several analysis steps were defined to perform the analysis sequentially. The nonlinear static solution was thereby progressed through the desired equilibrium conditions and the random response was determined as linear perturbation steps at the specified thermoelastic equilibrium states, i.e. $23.9^{\circ} \mathrm{C}\left(75^{\circ} \mathrm{F}\right), 65.6^{\circ} \mathrm{C}\left(150^{\circ} \mathrm{F}\right), 93.3^{\circ} \mathrm{C}\left(200^{\circ} \mathrm{F}\right), 121.1^{\circ} \mathrm{C}$ $\left(250^{\circ} \mathrm{F}\right)$. The geometric imperfections were introduced in the ABAQUS input file by using the *IMPERFECTION, FILE option to read the deflection data from the gravity analysis results file. All of the linear random response steps were again performed using the modal approach incorporating the first 10 modes, each with $0.5 \%$ critical damping ratio, and with a frequency resolution of $0.25 \mathrm{~Hz}$.

A comparison of the nonlinear static analysis results from MSC.Nastran, ABAQUS, and the research code is shown in Figure 4, which shows the mid-span out-of-plane deflection as a function of temperature using secant CTE thermal strain calculation. It can be seen that excellent agreement has been achieved between all three implementations of the ECTE model. Analogous results are shown in Figure 5 for two alternate thermal strain calculation cases. In the integral case, thermal strain is taken directly from tabulated data for the axial direction of the SMA (Equation (4)) and calculated by the integral method with tangent CTE data otherwise. Results for the strain case are generated by using thermal strain data for both directions in both materials; SMA and glass-epoxy. It can be seen that the results are essentially equivalent to the secant CTE results and excellent agreement between the codes is again achieved. Note that analysis was not possible in ABAQUS for the integral case and possible but not performed for the strain case. The results in both figures show that traditional thermoelastic behavior prevails up to a temperature of approximately $37.8^{\circ} \mathrm{C}\left(100^{\circ} \mathrm{F}\right)$, where the 
SMA actuation authority begins to dominate the stress state. At higher temperatures, the structure is rendered flat, even eliminating the initial imperfection (gravity) deflections. The stiffening effect dominates over a large temperature range, implying a significant effect on the dynamic response. More detailed descriptions of this complex thermoelastic behavior can be found in reference 5 .

Predictions from the three codes for the beam's linear random response at the two temperature extremes are shown in Figure 6 and Figure 7. The figures show the mid-span displacement power spectral density (PSD) versus frequency. Again, excellent correlation between the three codes is observed, as expected from the agreement between the nonlinear static analysis results. These results clearly demonstrate the large stiffening effect afforded by the SMA, which results in large shifts in the resonant frequencies and reductions in the dynamic response amplitude. For example, the fundamental frequency and RMS displacement response at $121.1^{\circ} \mathrm{C}\left(250^{\circ} \mathrm{F}\right)$ are $4.37 / 9.49$ times higher/lower than their reference temperature counterparts. Additional insight into the dynamic behavior of SMAHC structures is given in reference 13.

Similar analyses were conducted on a SMAHC beam specimen of a mix laminate type. Consider the same specimen geometry and layer orientations, but with a uniformly distributed mixture of SMA and glass-epoxy in the $0^{\circ}$ layers. This configuration is intended to simulate inclusion of small diameter round wire in the composite laminate. In this case, all layers were taken to have a thickness of $0.012383 \mathrm{~cm}(0.004875$ inches $)$, which gives an overall thickness of $0.198 \mathrm{~cm}(0.078$ inches) for all elements. A volume fraction of $55.38 \%$ SMA was specified for the $0^{\circ}$ layers to render an overall SMA volume fraction equivalent to the previous mon laminate case. Equations (7) were used with the specified volume fractions and the properties in Table 1 and Table 2 to generate 
effective properties for the $0^{\circ}$ SMAHC layers, shown in Table 3. These SMAHC effective properties were used, along with those for glass-epoxy alone, to construct the laminate properties for the model in Figure 3. Note that all elements in this finite element model share the same SMAHC properties of the mix laminate type, in contrast to the previous beam with SMA ribbon. A comparison of the thermal post-buckling (nonlinear static) results for this case is shown in Figure 8, where it can be seen that the maximum deflection has increased marginally and similar excellent agreement between the codes has been achieved. Similar performance between the two SMAHC laminate types was achieved intentionally in this case, but the utility of the modeling approach in achieving optimal designs is implied.

\subsection{Cantilever SMAHC Beam}

Focus is now directed to shape/deflection control of a cantilever SMAHC beam. Consider a cantilever SMAHC beam with a length and width of $22.86 \times 2.54 \mathrm{~cm}(9 \times 1$ inches $)$, or half of the model in Figure 3. A mon laminate case similar to that discussed previously is taken with the same stacking sequence $(45 / 0 /-45 / 90)_{2 \mathrm{~s}}$, but with SMA ribbon material replacing a width of $1.143 \mathrm{~cm}$ (0.45 inch) about the beam centerline in only the $2^{\text {nd }} 0^{\circ}$ glass-epoxy layer. Again, the outer 0.699 $\mathrm{cm}(0.275 \mathrm{inch})$ strips of the beam are modeled as solely glass-epoxy and the thickness of the glassepoxy and SMA are taken to be $0.012383 \mathrm{~cm}(0.004875 \mathrm{inch})$ and $0.015 \mathrm{~cm}(0.006 \mathrm{inch})$, respectively. Two element types are again required, one SMAHC and one glass-epoxy only, with overall thicknesses of $0.201 \mathrm{~cm}$ (0.079 inches) and $0.198 \mathrm{~cm}$ (0.078 inches), respectively. The material properties for the laminate constituents are given in Table 1 and Table 2 . The finite element model is subjected to a uniformly distributed thermal load of $121.1^{\circ} \mathrm{C}\left(250^{\circ} \mathrm{F}\right)$ to study the deflection response. No seeding of the deflection is necessary in this case due to the development of a thermal 
moment. Excellent agreement between MSC.Nastran and ABAQUS is apparent in the plot of tip displacement versus temperature shown in Figure 10. Excellent agreement between the three thermal strain calculation methods in MSC.Nastran is also demonstrated.

A similar comparison is shown in Figure 11 for the analogous mix laminate case of uniformly distributed SMA throughout the $2^{\text {nd }} 0^{\circ}$ layer, which was modeled by a $55.38 \%$ SMA volume fraction in the single SMAHC layer of $0.012383 \mathrm{~cm}(0.004875$ inch) thickness. In this case all finite elements have the same lamination, overall thickness of $0.198 \mathrm{~cm}(0.078$ inches $)$, and material properties given in Table 1 and Table 3. It can be seen that excellent correlation is achieved between MSC.Nastran and ABAQUS for this case also. These results again demonstrate the actuation authority of the SMA and indicate that large deflections are possible using relatively little SMA. Results from the research code are excluded from the deflection control comparisons because the response is beyond the scope of the formulation.

The deflection control example provides an introduction to the concept of shape control of structures by embedded SMA actuation. This topic is currently of significant interest for a variety of advanced aerospace vehicle applications, e.g., see references 16 and 17. Note that use of the ECTE model for shape control applications should be limited to cases in which the recovered strain of the SMA actuators is small relative to the prestrain, unless accommodations are made to schedule diminishing actuation authority. Also, prediction of the response during unloading requires data in addition to that in Table 1-Table 3 because of the hysteresis inherent to SMA materials. 
Extensive additional detail on the analysis input files and solution procedures for the cases presented in this study are available in reference 14. ASCII listings of all of the input files and data necessary to duplicate the results in this document are also available in that reference, as well as in electronoic form at the URL http://stabserv.larc.nasa.gov.

\section{SUMMARY AND CONCLUSIONS}

A thermoelastic model for shape memory alloy (SMA) and SMA hybrid composite (SMAHC) materials has been implemented in the commercial finite element codes MSC.Nastran and ABAQUS. The model is based upon definition of an effective coefficient of thermal expansion (ECTE). The model can be readily implemented in any code that has capability for structural analysis with temperature dependent material properties. The model was applied to two different types of SMAHC laminated materials, corresponding to inclusion of SMA actuators in ribbon and round wire product forms. The SMA ribbon inclusion material model resulted in finite elements with layers composed of either host composite material or SMA material alone. The model for inclusion of round SMA wire required calculation of effective properties for mixtures of host composite and SMA in the finite element layers. This calculation can be performed automatically in a suitable finite element pre-processor. Alternatively, the effective properties can be calculated externally, e.g., using the formulation presented in this document, from the constituent properties and hand entered into the analysis input files.

SMAHC structural analysis was demonstrated on SMAHC beams of two types; a beam clamped at both ends and a cantilever beam. Results from nonlinear static (post-buckling) and random vibration responses of the first specimen type showed excellent correlation between the two commercial 
implementations and the research code. Complex thermoelastic behavior and the enormous control authority of the SMA actuators were demonstrated. Three different forms of thermal strain calculation in MSC.Nastran were shown to produce equivalent results, as expected. Analysis of the two different SMAHC material configurations, one involving large cross section aspect ratio SMA ribbon and another involving small diameter SMA wire, showed similar response and equally good analysis comparison with implications for parametric studies and/or optimal design. Analysis of the cantilever specimen introduced the use of the ECTE model for shape control prediction. Again, results are presented from analysis of two material configurations. The deflection of the cantilever beam in response to heating demonstrated the efficient control authority of the embedded SMA.

Excellent correlation was achieved between the two commercial codes.

\section{REFERENCES}

1. J. G. Boyd and D. C. Lagoudas, "A Thermodynamical Constitutive Model for Shape Memory Materials - Part I: The Monolithic Shape Memory Alloy”, Int. J. of Plasticity, 12(7), 805-842, 1996.

2. J. G. Boyd and D. C. Lagoudas, "A Thermodynamical Constitutive Model for Shape Memory Materials - Part I: The SMA Composite Material," Int. J. of Plasticity, 12(7), 843-873, 1996

3. X. Gao, M. Huang, and L. C. Brinson, "A Multivariant Micromechanical Model for SMAs Part 1. Crystallographic Issues for Single Crystal Model," International Journal of Plasticity, 16, $1345-1369,2000$.

4. M. Huang, X. Gao, and L. C. Brinson, "A Multivariant Micromechanical Model for SMAs Part 1. Polycrystal Model," International Journal of Plasticity, 16, 1371-1390, 2000

5. T. L. Turner, "A New Thermoelastic Model for Analysis of Shape Memory Alloy Hybrid Composites," Journal of Intelligent Material Systems and Structures, 11, 382-394, May 2000.

6. C. A. Rogers and H. H. Robertshaw, "Shape Memory Alloy Reinforced Composites," Engineering Science Preprints, 25, Society of Engineering Science, Inc., ESP25.8027, 1988.

7. T. L. Turner, Z. Zhong, and C. Mei, "Finite Element Analysis of the Random Response Suppression of Composite Panels at Elevated Temperatures using Shape Memory Alloy Fibers," in Proceedings of $35^{\text {th }}$ Structures, Structural Dynamics, and Materials Conf., AIAA-94-1324CP, Hilton Head, SC, 1994.

8. J. Ro and A. Baz, "Nitinol-Reinforced Plates: Part II. Static and Buckling Characteristics," Composites Engineering, 5(1), 77-90, 1995.

9. J. Ro and A. Baz, "Nitinol-Reinforced Plates: Part III. Dynamic Characteristics," Composites Engineering, 5(1), 91-106, 1995. 
10. M. Tawfik, J. J. Ro, and C. Mei, "Thermal Post-buckling and Aeroelastic Behavior of Shape Memory Alloy Reinforced Plates," Smart Materials and Structures, 11, 297-307, 2002.

11. S. P. Thompson and J. Loughlan, "Enhancing the Post-buckling Response of a Composite Panel Structure Utilizing Shape Memory Alloy Actuators - A Smart Structural Concept," Composite Structures, 51, 21-36, 2001.

12. T. L. Turner,"Experimental Validation of a Thermoelastic Model for SMA Hybrid Composites," in Smart Structures and Materials: Modeling, Signal Processing, and Control in Smart Structures, V. S. Rao, Editor, Proceedings of SPIE Vol. 4326, 208-219 (2001).

13. T. L. Turner, "SMA Hybrid Composites for Dynamic Response Abatement Applications," accepted ASME Journal of Vibration and Acoustics, October 2004.

14. T. L. Turner and H. D. Patel, "Input Files and Procedures for Analysis of SMA Hybrid Composite Beams in MSC.Nastran and ABAQUS," NASA/TM-2005-213517, January 2005.

15. T. Y. Yang, Finite Element Structural Analysis, 423-425, Prentice-Hall, Inc., Englewood Cliffs, New Jersey, 1986.

16. T. L. Turner, R. H. Buehrle, R. J. Cano, and G. A. Fleming, "Design, Fabrication, and Testing of SMA Enabled Adaptive Chevrons for Jet Noise Reduction," in Smart Structures and Materials: Smart Structures and Integrated Systems, A. B. Flatau, Editor, Proceedings of SPIE Vol. 5390, 297-308 (2004).

17. T. L. Turner, R. H. Buehrle, R. J. Cano, and G. A. Fleming, "Modeling, Fabrication, and Testing of a SMA Hybrid Composite Jet Engine Chevron Concept," in proceedings of The 2004 International Symposium on Active Control of Sound and Vibration (ACTIVE 04), INCE/USA, Williamsburg, VA, 20-22 September 2004. 


\section{SYMBOLS}
A Transformation temperature
E Elastic modulus
$\mathrm{G}$ hear modulus
Q Composite lamina reduced stiffness
$\mathrm{T}$ Temperature

Greek

$\alpha \quad$ Coefficient of thermal expansion

$\gamma \quad$ Engineering shear strain

$\varepsilon \quad$ Normal strain

$v \quad$ Poisson's ratio

$\sigma \quad$ Normal stress

$\tau \quad$ Shear stress

\section{Subscripts}

1,2,6 Orthotropic tensor indices in contracted notation

a Associated with actuator material

$\mathrm{m} \quad$ Associated with matrix material

o Ambient or reference quantity

ref Reference quantity

s Indicates transformation start 
Figure 1: Representative volume element for a SMAHC lamina.

Figure 2: Representative beam cross sections for the mon (a) and mix (b) SMAHC laminate types.

Figure 3: SMAHC beam clamped at both ends with finite element mesh.

Figure 4: Post-buckling deflection versus temperature for the mon laminate case using secant CTE data.

Figure 5: Post-buckling deflection versus temperature for the mon laminate case using combination tangent CTE/thermal strain data and all-thermal strain data.

Figure 6: Random inertial mid-span displacement response PSD at $23.9^{\circ} \mathrm{C}\left(75^{\circ} \mathrm{F}\right)$ for the $m o n$ laminate case.

Figure 7: Random inertial mid-span displacement response PSD at $121.1^{\circ} \mathrm{C}\left(250^{\circ} \mathrm{F}\right)$ for the $m o n$ laminate case.

Figure 8: Post-buckling deflection versus temperature for the mix laminate case using secant CTE data.

Figure 9: SMAHC cantilever beam with finite element mesh.

Figure 10: Tip deflection versus temperature for the mon laminate case using secant CTE, combination tangent CTE/thermal strain data, and all-thermal strain data types.

Figure 11: Tip deflection versus temperature for the mix laminate case using secant CTE, combination tangent CTE/thermal strain, and all-thermal strain data types. 


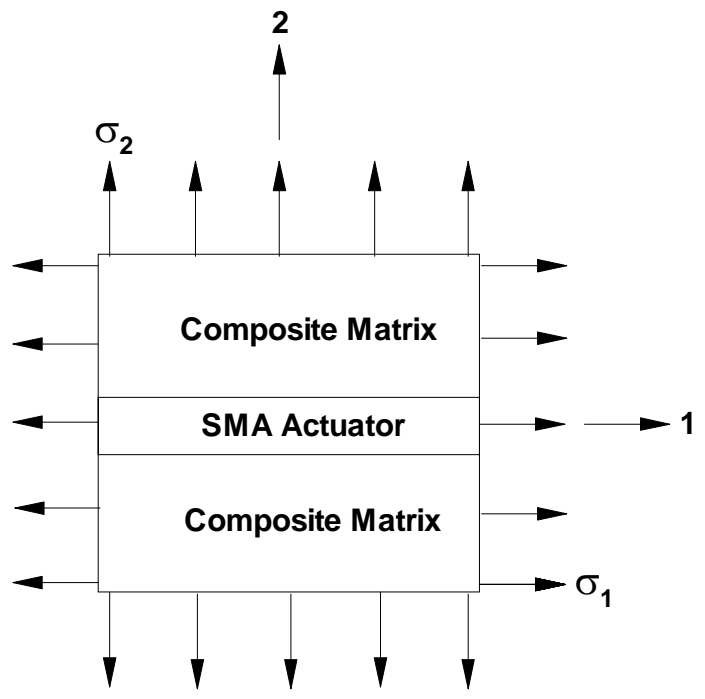

Figure 1: Representative volume element for a SMAHC lamina 


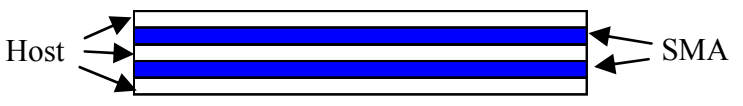

(a)

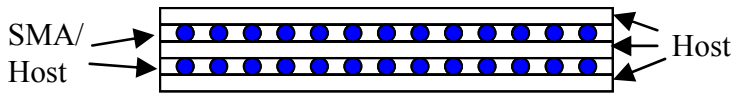

(b)

Figure 2: Representative beam cross sections for the mon (a) and mix (b) SMAHC laminate types. 


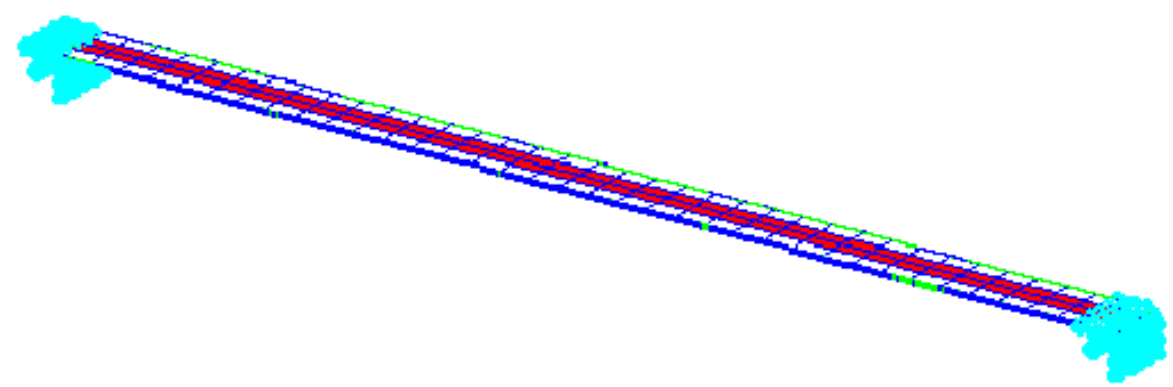

Figure 3: SMAHC beam clamped at both ends with finite element mesh. 


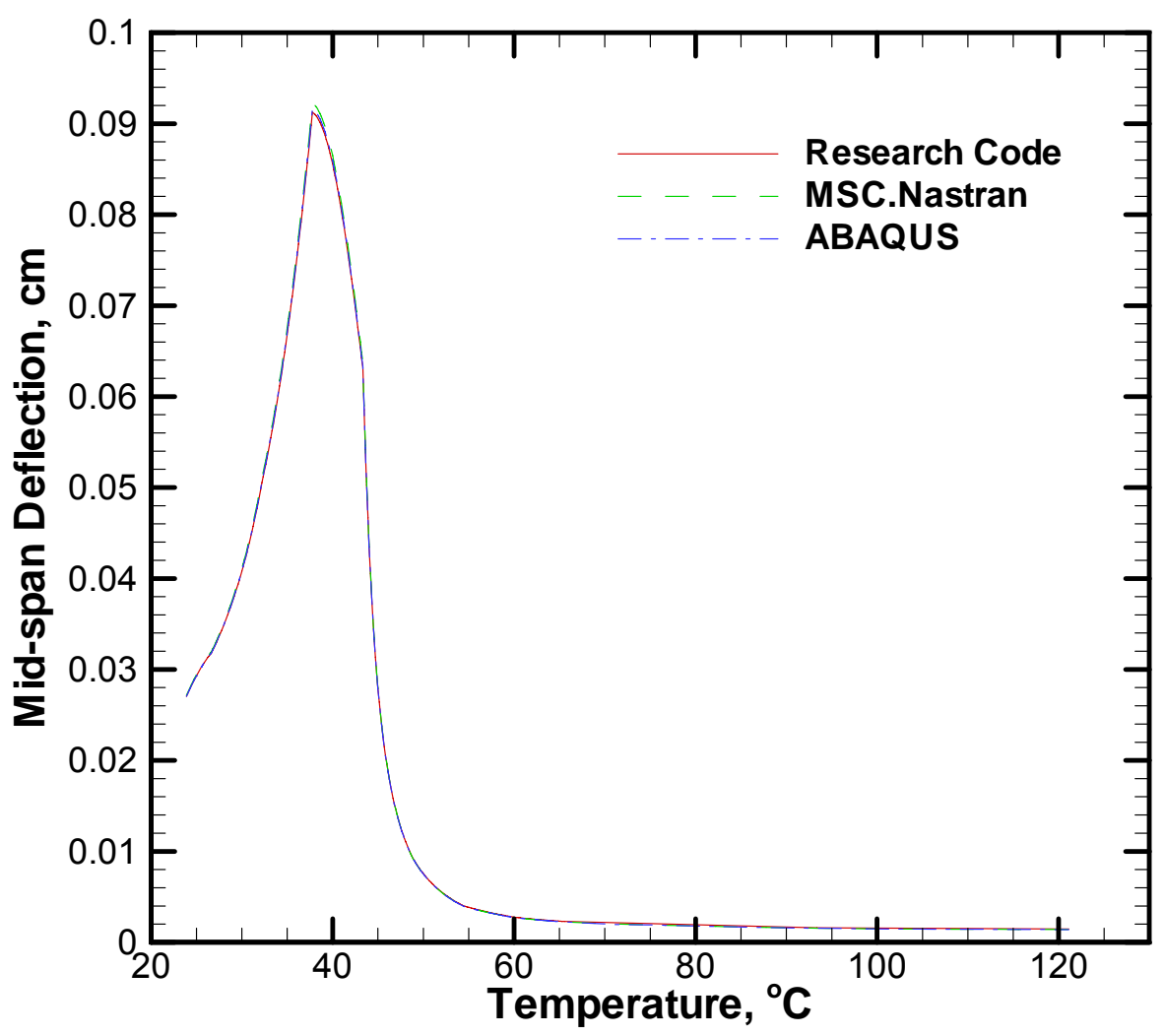

Figure 4: Post-buckling deflection versus temperature for the mon laminate case using secant CTE data. 


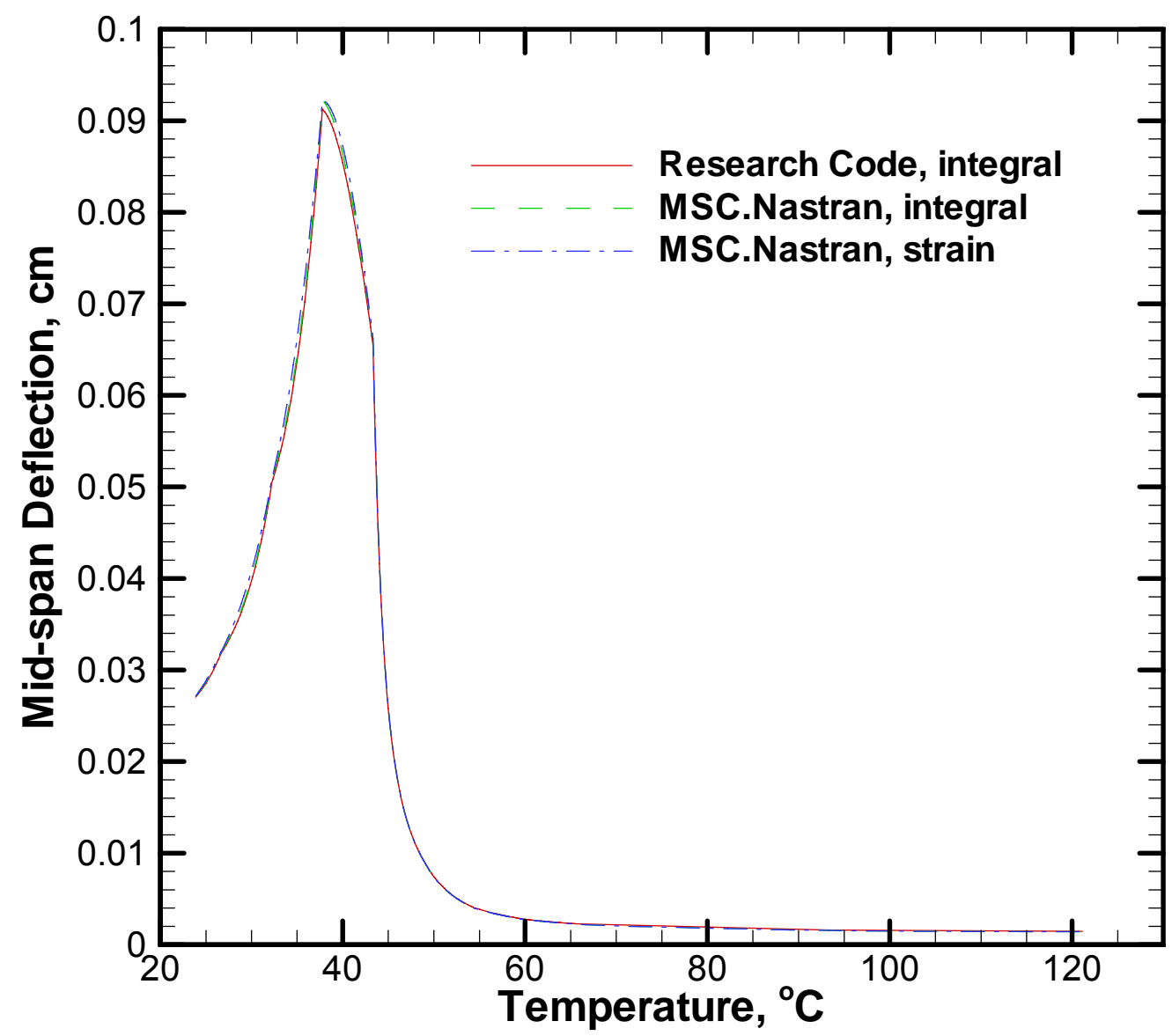

Figure 5: Post-buckling deflection versus temperature for the mon laminate case using combination tangent CTE/thermal strain data and all-thermal strain data. 


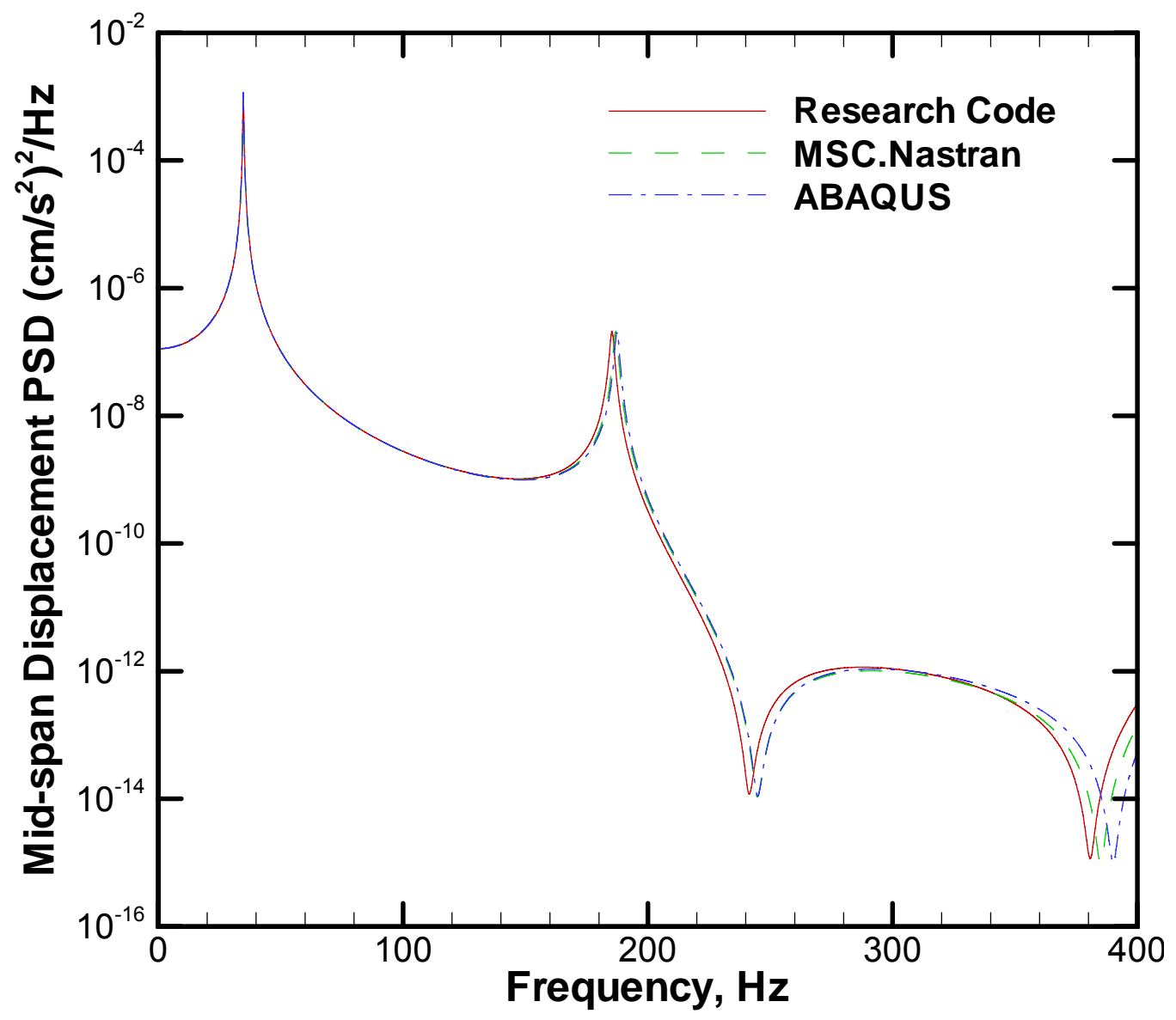

Figure 6: Random inertial mid-span displacement response PSD at $23.9^{\circ} \mathrm{C}\left(75^{\circ} \mathrm{F}\right)$ for the mon laminate case. 


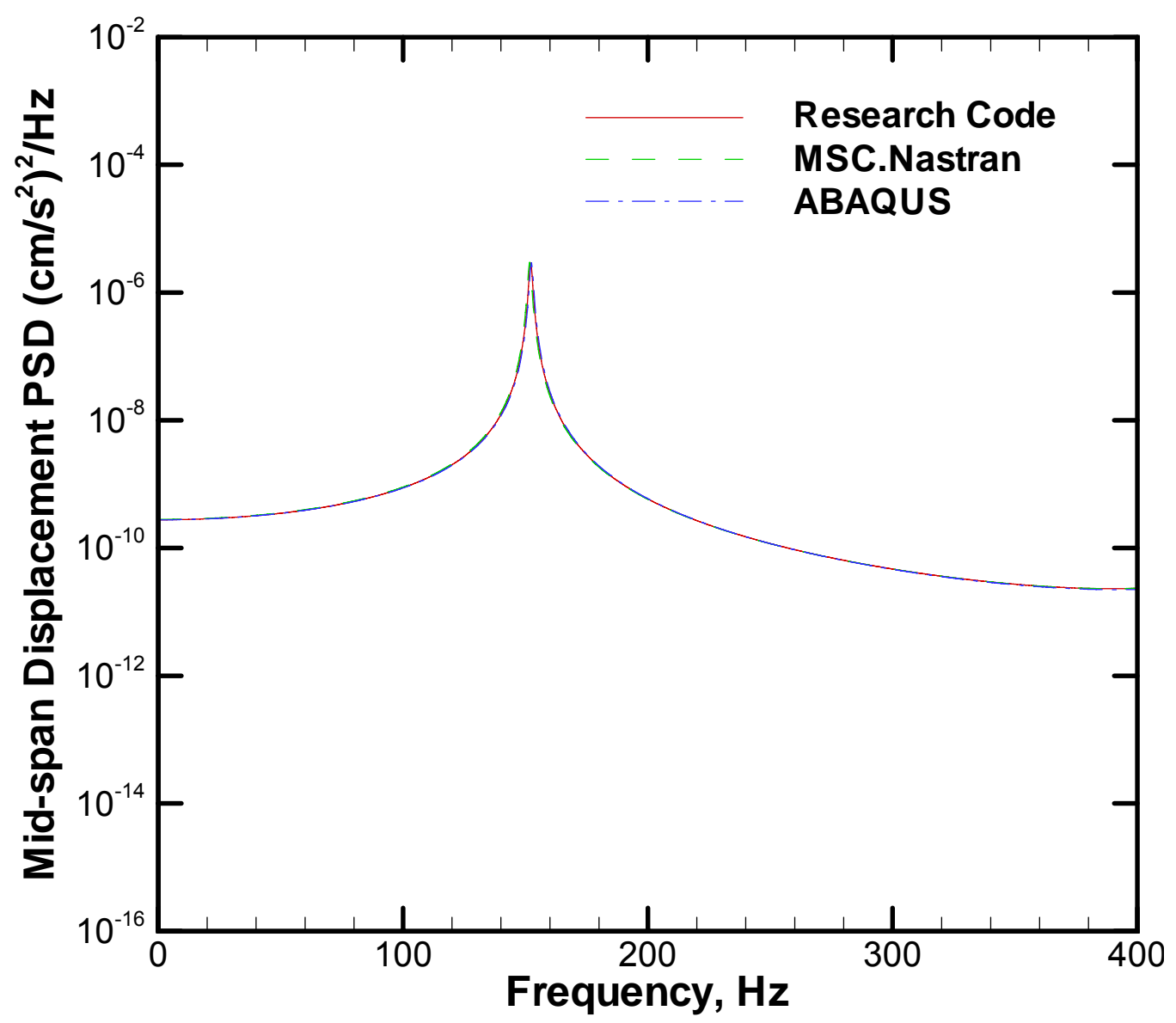

Figure 7: Random inertial mid-span displacement response PSD at $121.1{ }^{\circ} \mathrm{C}\left(250^{\circ} \mathrm{F}\right)$ for the mon laminate case. 


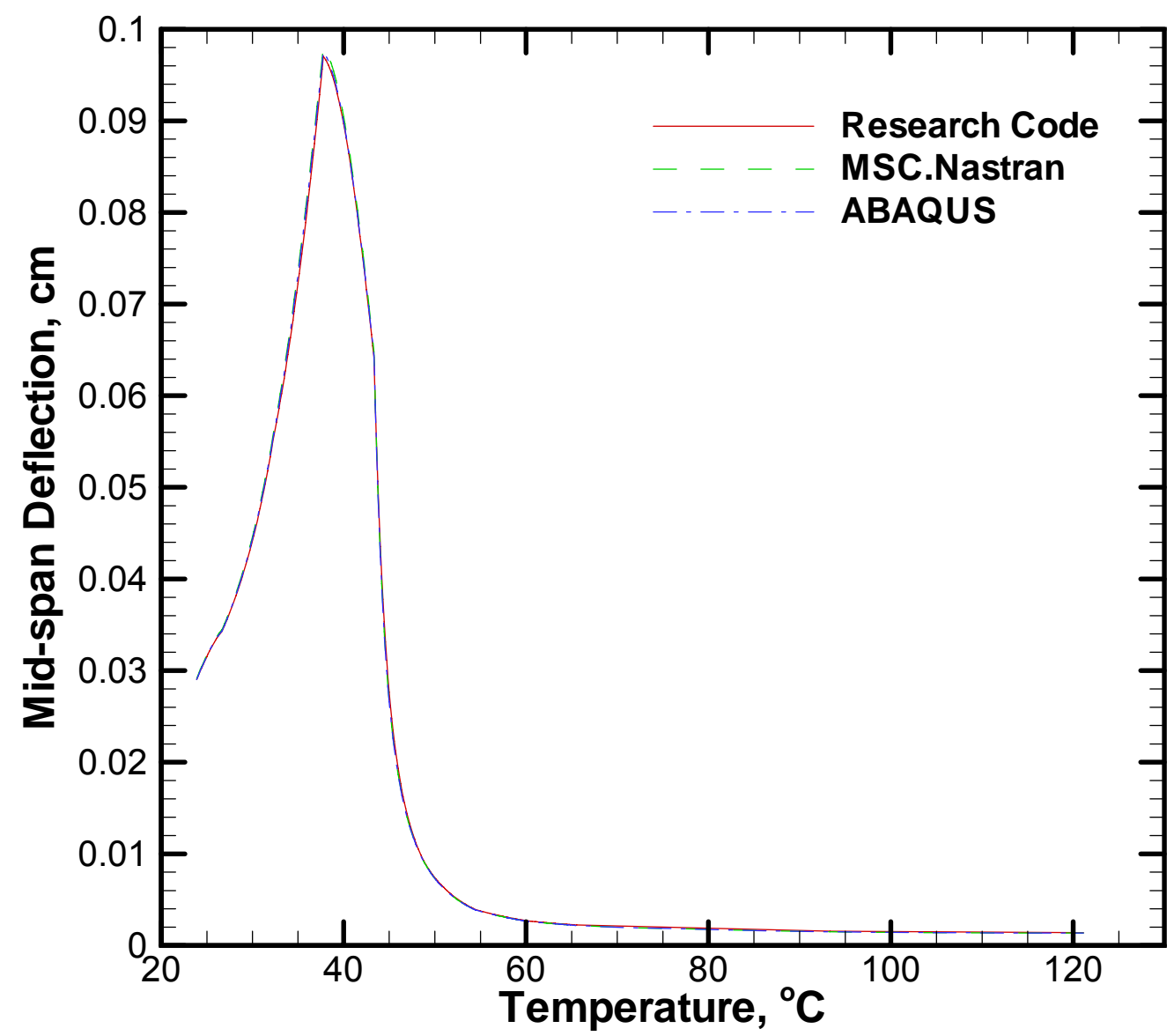

Figure 8: Post-buckling deflection versus temperature for the mix laminate case using secant CTE data. 


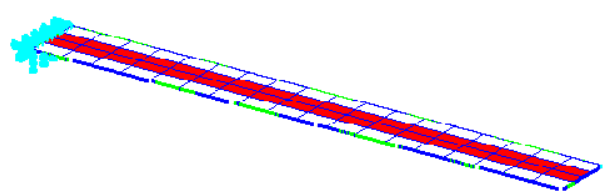

Figure 9: SMAHC cantilever beam with finite element mesh. 


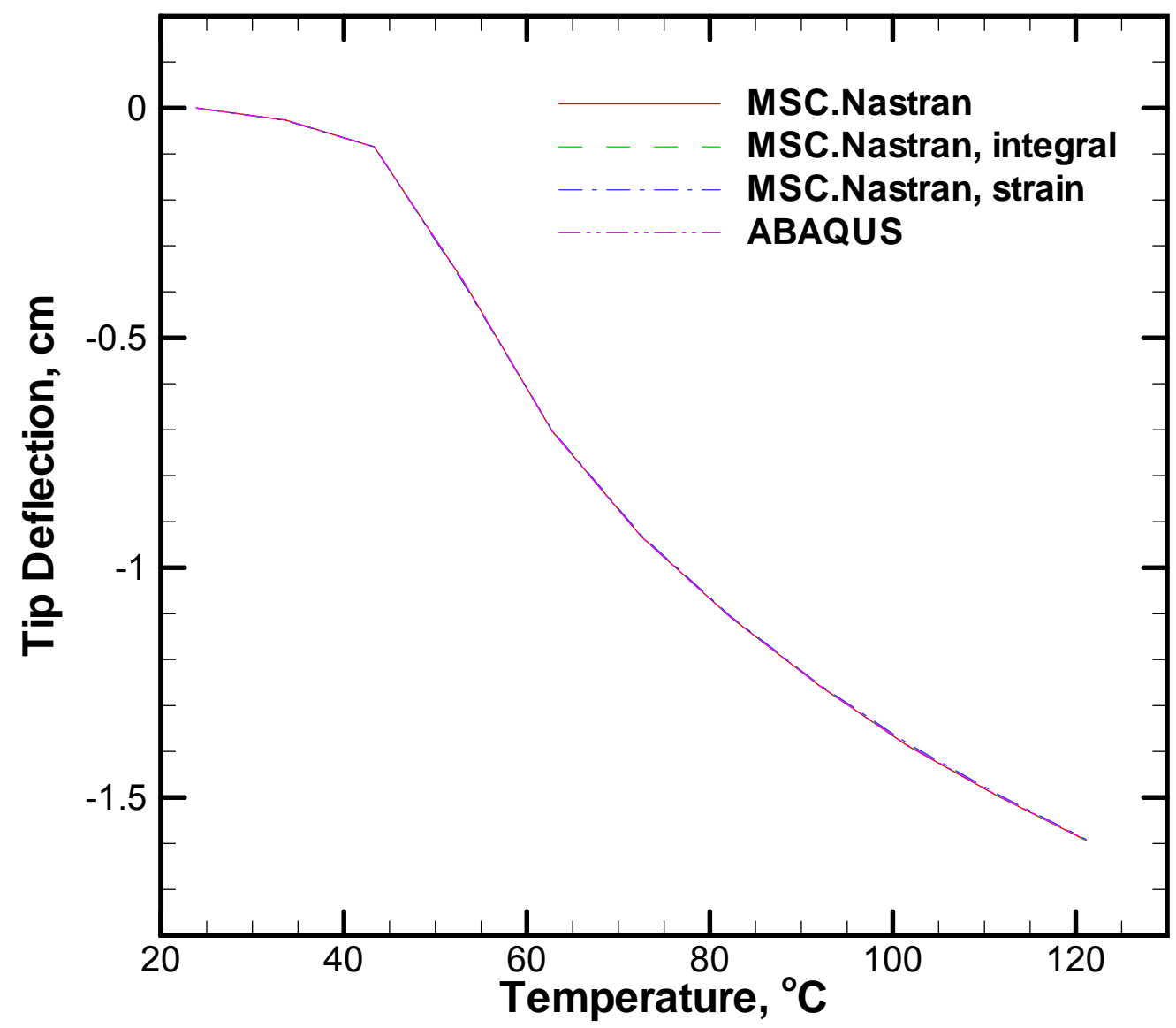

Figure 10: Tip deflection versus temperature for the mon laminate case using secant CTE, combination tangent $\mathrm{CTE} /$ thermal strain, and all-thermal strain data types. 


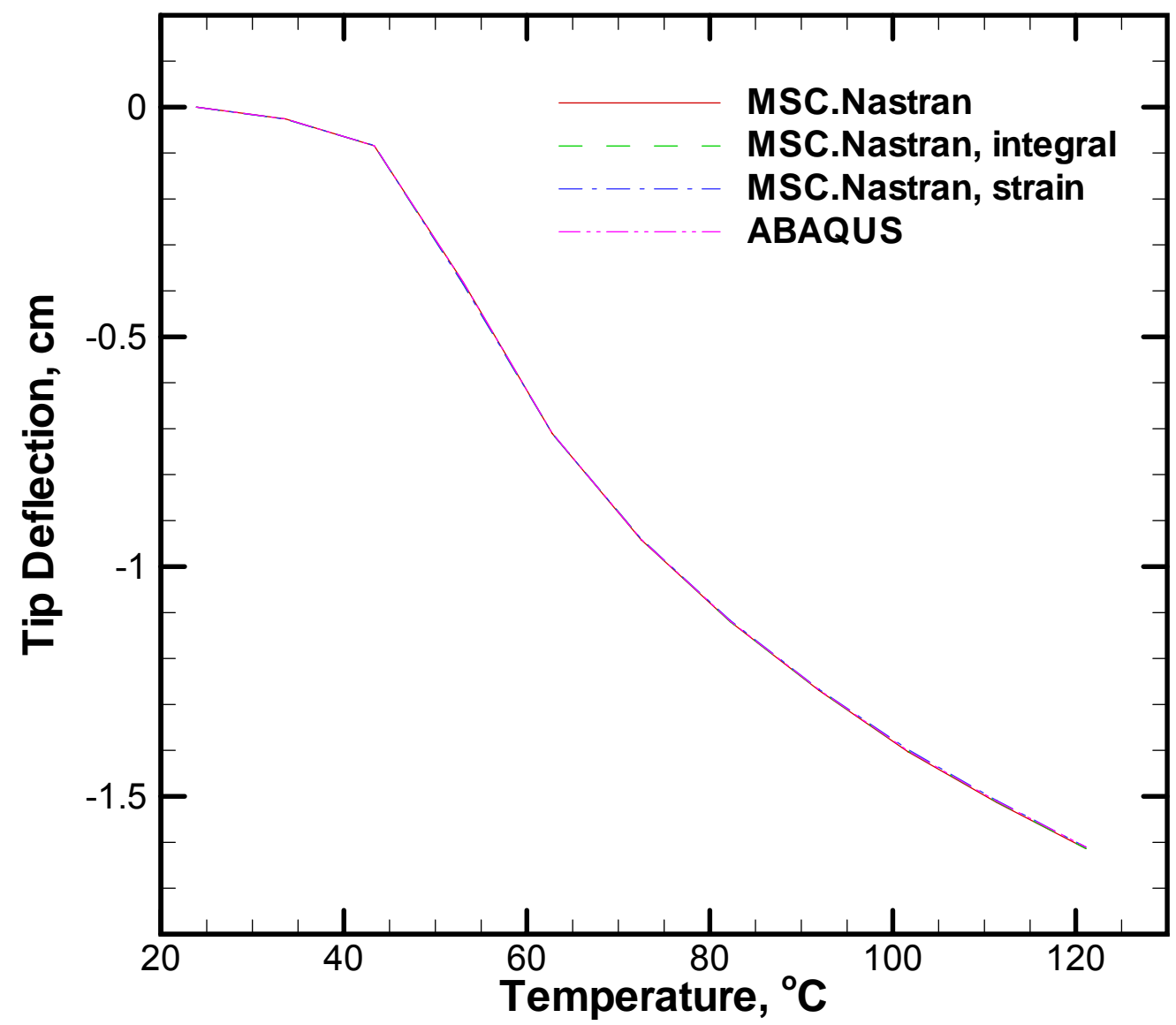

Figure 11: Tip deflection versus temperature for the mix laminate case using secant CTE, combination tangent $\mathrm{CTE} /$ thermal strain, and all-thermal strain data types. 
Table 1: Temperature dependent orthotropic material properties for glass-epoxy $\left(\rho=5.259 \mathrm{E}-3 \mathrm{~g} / \mathrm{cm}^{3}\right.$, secant CTE data presented with $\mathrm{T}_{\text {ref }}=23.9^{\circ} \mathrm{C}$ ).

$\begin{array}{ccccccc}\mathrm{T},{ }^{\circ} \mathrm{C} & \alpha_{1}, /{ }^{\circ} \mathrm{C} & \alpha_{2}, /{ }^{\circ} \mathrm{C} & \mathrm{E}_{1}, \mathrm{~Pa} & \mathrm{E}_{2}, \mathrm{~Pa} & \mathrm{G}_{12}, \mathrm{~Pa} & \mathrm{v}_{12} \\ 15.6 & 5.270 \mathrm{E}-06 & 1.105 \mathrm{E}-05 & 4.930 \mathrm{E}+10 & 2.000 \mathrm{E}+10 & 9.653 \mathrm{E}+09 & 0.29 \\ 21.1 & 5.373 \mathrm{E}-06 & 1.155 \mathrm{E}-05 & 4.930 \mathrm{E}+10 & 2.000 \mathrm{E}+10 & 9.653 \mathrm{E}+09 & 0.29 \\ 26.7 & 5.679 \mathrm{E}-06 & 1.306 \mathrm{E}-05 & 4.930 \mathrm{E}+10 & 2.000 \mathrm{E}+10 & 9.653 \mathrm{E}+09 & 0.29 \\ 32.2 & 5.963 \mathrm{E}-06 & 1.480 \mathrm{E}-05 & 4.923 \mathrm{E}+10 & 1.972 \mathrm{E}+10 & 9.446 \mathrm{E}+09 & 0.29 \\ 37.8 & 6.248 \mathrm{E}-06 & 1.654 \mathrm{E}-05 & 4.916 \mathrm{E}+10 & 1.944 \mathrm{E}+10 & 9.239 \mathrm{E}+09 & 0.29 \\ 43.3 & 6.433 \mathrm{E}-06 & 1.788 \mathrm{E}-05 & 4.909 \mathrm{E}+10 & 1.920 \mathrm{E}+10 & 9.067 \mathrm{E}+09 & 0.29 \\ 48.9 & 6.619 \mathrm{E}-06 & 1.922 \mathrm{E}-05 & 4.902 \mathrm{E}+10 & 1.896 \mathrm{E}+10 & 8.895 \mathrm{E}+09 & 0.29 \\ 54.4 & 6.694 \mathrm{E}-06 & 2.003 \mathrm{E}-05 & 4.892 \mathrm{E}+10 & 1.872 \mathrm{E}+10 & 8.722 \mathrm{E}+09 & 0.29 \\ 60.0 & 6.770 \mathrm{E}-06 & 2.083 \mathrm{E}-05 & 4.882 \mathrm{E}+10 & 1.848 \mathrm{E}+10 & 8.550 \mathrm{E}+09 & 0.29 \\ 65.6 & 6.788 \mathrm{E}-06 & 2.131 \mathrm{E}-05 & 4.875 \mathrm{E}+10 & 1.820 \mathrm{E}+10 & 8.412 \mathrm{E}+09 & 0.29 \\ 71.1 & 6.779 \mathrm{E}-06 & 2.164 \mathrm{E}-05 & 4.875 \mathrm{E}+10 & 1.779 \mathrm{E}+10 & 8.274 \mathrm{E}+09 & 0.29 \\ 76.7 & 6.751 \mathrm{E}-06 & 2.180 \mathrm{E}-05 & 4.871 \mathrm{E}+10 & 1.741 \mathrm{E}+10 & 8.102 \mathrm{E}+09 & 0.29 \\ 82.2 & 6.723 \mathrm{E}-06 & 2.196 \mathrm{E}-05 & 4.868 \mathrm{E}+10 & 1.703 \mathrm{E}+10 & 7.929 \mathrm{E}+09 & 0.29 \\ 87.8 & 6.688 \mathrm{E}-06 & 2.200 \mathrm{E}-05 & 4.864 \mathrm{E}+10 & 1.662 \mathrm{E}+10 & 7.757 \mathrm{E}+09 & 0.29 \\ 93.3 & 6.653 \mathrm{E}-06 & 2.203 \mathrm{E}-05 & 4.861 \mathrm{E}+10 & 1.620 \mathrm{E}+10 & 7.585 \mathrm{E}+09 & 0.29 \\ 98.9 & 6.630 \mathrm{E}-06 & 2.202 \mathrm{E}-05 & 4.861 \mathrm{E}+10 & 1.576 \mathrm{E}+10 & 7.171 \mathrm{E}+09 & 0.29 \\ 104.4 & 6.608 \mathrm{E}-06 & 2.201 \mathrm{E}-05 & 4.861 \mathrm{E}+10 & 1.531 \mathrm{E}+10 & 6.757 \mathrm{E}+09 & 0.29 \\ 110.0 & 6.606 \mathrm{E}-06 & 2.203 \mathrm{E}-05 & 4.858 \mathrm{E}+10 & 1.486 \mathrm{E}+10 & 6.378 \mathrm{E}+09 & 0.29 \\ 115.6 & 6.604 \mathrm{E}-06 & 2.205 \mathrm{E}-05 & 4.854 \mathrm{E}+10 & 1.441 \mathrm{E}+10 & 5.999 \mathrm{E}+09 & 0.29 \\ 121.1 & 6.619 \mathrm{E}-06 & 2.210 \mathrm{E}-05 & 4.854 \mathrm{E}+10 & 1.400 \mathrm{E}+10 & 5.585 \mathrm{E}+09 & 0.29 \\ 126.7 & 6.644 \mathrm{E}-06 & 2.219 \mathrm{E}-05 & 4.861 \mathrm{E}+10 & 1.345 \mathrm{E}+10 & 5.171 \mathrm{E}+09 & 0.29 \\ 132.2 & 6.675 \mathrm{E}-06 & 2.232 \mathrm{E}-05 & 4.864 \mathrm{E}+10 & 1.293 \mathrm{E}+10 & 4.723 \mathrm{E}+09 & 0.29 \\ 137.8 & 6.707 \mathrm{E}-06 & 2.245 \mathrm{E}-05 & 4.868 \mathrm{E}+10 & 1.241 \mathrm{E}+10 & 4.275 \mathrm{E}+09 & 0.29 \\ 143.3 & 6.744 \mathrm{E}-06 & 2.260 \mathrm{E}-05 & 4.875 \mathrm{E}+10 & 1.189 \mathrm{E}+10 & 3.861 \mathrm{E}+09 & 0.29 \\ 148.9 & 6.781 \mathrm{E}-06 & 2.275 \mathrm{E}-05 & 4.882 \mathrm{E}+10 & 1.138 \mathrm{E}+10 & 3.448 \mathrm{E}+09 & 0.29\end{array}$


Table 2: Temperature dependent orthotropic material properties for Nitinol $\left(\rho=1.481 \mathrm{E}-2 \mathrm{~g} / \mathrm{cm}^{3}\right.$, secant CTE data presented with $\mathrm{T}_{\text {ref }}=23.9^{\circ} \mathrm{C}$ ).

$\begin{array}{rcccccc}\mathrm{T},{ }^{\circ} \mathrm{C} & \mathrm{\alpha}_{1}, /{ }^{\circ} \mathrm{C} & \mathrm{a}_{2},{ }^{\circ} \mathrm{C} & \mathrm{E}_{1}, \mathrm{~Pa} & \mathrm{E}_{2}, \mathrm{~Pa} & \mathrm{G}_{12}, \mathrm{~Pa} & \mathrm{v}_{12} \\ 15.6 & 6.606 \mathrm{E}-06 & 6.606 \mathrm{E}-06 & 2.717 \mathrm{E}+10 & 2.717 \mathrm{E}+10 & 1.045 \mathrm{E}+10 & 0.3 \\ 21.1 & 6.606 \mathrm{E}-06 & 6.606 \mathrm{E}-06 & 2.717 \mathrm{E}+10 & 2.717 \mathrm{E}+10 & 1.045 \mathrm{E}+10 & 0.3 \\ 26.7 & -3.089 \mathrm{E}-05 & 6.606 \mathrm{E}-06 & 2.480 \mathrm{E}+10 & 2.480 \mathrm{E}+10 & 9.538 \mathrm{E}+09 & 0.3 \\ 32.2 & -3.871 \mathrm{E}-05 & 6.606 \mathrm{E}-06 & 2.243 \mathrm{E}+10 & 2.243 \mathrm{E}+10 & 8.628 \mathrm{E}+09 & 0.3 \\ 37.8 & -5.040 \mathrm{E}-05 & 6.606 \mathrm{E}-06 & 2.006 \mathrm{E}+10 & 2.006 \mathrm{E}+10 & 7.717 \mathrm{E}+09 & 0.3 \\ 43.3 & -5.705 \mathrm{E}-05 & 6.606 \mathrm{E}-06 & 2.570 \mathrm{E}+10 & 2.570 \mathrm{E}+10 & 9.886 \mathrm{E}+09 & 0.3 \\ 48.9 & -1.005 \mathrm{E}-04 & 6.676 \mathrm{E}-06 & 3.134 \mathrm{E}+10 & 3.134 \mathrm{E}+10 & 1.206 \mathrm{E}+10 & 0.3 \\ 54.4 & -1.345 \mathrm{E}-04 & 6.834 \mathrm{E}-06 & 3.698 \mathrm{E}+10 & 3.698 \mathrm{E}+10 & 1.423 \mathrm{E}+10 & 0.3 \\ 60.0 & -1.416 \mathrm{E}-04 & 7.040 \mathrm{E}-06 & 4.262 \mathrm{E}+10 & 4.262 \mathrm{E}+10 & 1.639 \mathrm{E}+10 & 0.3 \\ 65.6 & -1.340 \mathrm{E}-04 & 7.275 \mathrm{E}-06 & 4.827 \mathrm{E}+10 & 4.827 \mathrm{E}+10 & 1.856 \mathrm{E}+10 & 0.3 \\ 71.1 & -1.196 \mathrm{E}-04 & 7.529 \mathrm{E}-06 & 5.486 \mathrm{E}+10 & 5.486 \mathrm{E}+10 & 2.110 \mathrm{E}+10 & 0.3 \\ 76.7 & -1.053 \mathrm{E}-04 & 7.795 \mathrm{E}-06 & 6.145 \mathrm{E}+10 & 6.145 \mathrm{E}+10 & 2.363 \mathrm{E}+10 & 0.3 \\ 82.2 & -9.932 \mathrm{E}-05 & 8.070 \mathrm{E}-06 & 6.421 \mathrm{E}+10 & 6.421 \mathrm{E}+10 & 2.469 \mathrm{E}+10 & 0.3 \\ 87.8 & -9.898 \mathrm{E}-05 & 8.325 \mathrm{E}-06 & 6.313 \mathrm{E}+10 & 6.313 \mathrm{E}+10 & 2.428 \mathrm{E}+10 & 0.3 \\ 93.3 & -9.719 \mathrm{E}-05 & 8.538 \mathrm{E}-06 & 6.206 \mathrm{E}+10 & 6.206 \mathrm{E}+10 & 2.387 \mathrm{E}+10 & 0.3 \\ 98.9 & -9.127 \mathrm{E}-05 & 8.721 \mathrm{E}-06 & 6.392 \mathrm{E}+10 & 6.392 \mathrm{E}+10 & 2.458 \mathrm{E}+10 & 0.3 \\ 104.4 & -8.458 \mathrm{E}-05 & 8.878 \mathrm{E}-06 & 6.578 \mathrm{E}+10 & 6.578 \mathrm{E}+10 & 2.530 \mathrm{E}+10 & 0.3 \\ 110.0 & -7.877 \mathrm{E}-05 & 9.015 \mathrm{E}-06 & 6.764 \mathrm{E}+10 & 6.764 \mathrm{E}+10 & 2.602 \mathrm{E}+10 & 0.3 \\ 115.6 & -7.335 \mathrm{E}-05 & 9.135 \mathrm{E}-06 & 6.950 \mathrm{E}+10 & 6.950 \mathrm{E}+10 & 2.673 \mathrm{E}+10 & 0.3 \\ 121.1 & -6.816 \mathrm{E}-05 & 9.241 \mathrm{E}-06 & 7.136 \mathrm{E}+10 & 7.136 \mathrm{E}+10 & 2.745 \mathrm{E}+10 & 0.3 \\ 126.7 & -6.576 \mathrm{E}-05 & 9.336 \mathrm{E}-06 & 7.084 \mathrm{E}+10 & 7.084 \mathrm{E}+10 & 2.725 \mathrm{E}+10 & 0.3 \\ 132.2 & -6.325 \mathrm{E}-05 & 9.421 \mathrm{E}-06 & 7.032 \mathrm{E}+10 & 7.032 \mathrm{E}+10 & 2.704 \mathrm{E}+10 & 0.3 \\ 137.8 & -6.104 \mathrm{E}-05 & 9.498 \mathrm{E}-06 & 6.979 \mathrm{E}+10 & 6.979 \mathrm{E}+10 & 2.684 \mathrm{E}+10 & 0.3 \\ 143.3 & -5.890 \mathrm{E}-05 & 9.568 \mathrm{E}-06 & 6.927 \mathrm{E}+10 & 6.927 \mathrm{E}+10 & 2.664 \mathrm{E}+10 & 0.3 \\ 148.9 & -5.711 \mathrm{E}-05 & 9.632 \mathrm{E}-06 & 6.874 \mathrm{E}+10 & 6.874 \mathrm{E}+10 & 2.644 \mathrm{E}+10 & 0.3\end{array}$


Table 3: Temperature dependent orthotropic material properties for SMAHC mixture with 55.38\% SMA content $\left(\rho=1.055 \mathrm{E}-2 \mathrm{~g} / \mathrm{cm}^{3}\right.$, secant CTE data presented with $\left.\mathrm{T}_{\text {ref }}=23.9^{\circ} \mathrm{C}\right)$.

$\begin{array}{ccccccc}\mathrm{T},{ }^{\circ} \mathrm{C} & \mathrm{\alpha}_{1}, /{ }^{\circ} \mathrm{C} & \mathrm{\alpha}_{2}, /{ }^{\circ} \mathrm{C} & \mathrm{E}_{1}, \mathrm{~Pa} & \mathrm{E}_{2}, \mathrm{~Pa} & \mathrm{G}_{12}, \mathrm{~Pa} & \mathrm{v}_{12} \\ 15.6 & 5.813 \mathrm{E}-06 & 8.589 \mathrm{E}-06 & 3.704 \mathrm{E}+10 & 2.342 \mathrm{E}+10 & 1.008 \mathrm{E}+10 & 0.296 \\ 21.1 & 5.874 \mathrm{E}-06 & 8.812 \mathrm{E}-06 & 3.704 \mathrm{E}+10 & 2.342 \mathrm{E}+10 & 1.008 \mathrm{E}+10 & 0.296 \\ 26.7 & -8.380 \mathrm{E}-06 & 9.483 \mathrm{E}-06 & 3.573 \mathrm{E}+10 & 2.240 \mathrm{E}+10 & 9.589 \mathrm{E}+09 & 0.296 \\ 32.2 & -1.018 \mathrm{E}-05 & 1.026 \mathrm{E}-05 & 3.439 \mathrm{E}+10 & 2.114 \mathrm{E}+10 & 8.975 \mathrm{E}+09 & 0.296 \\ 37.8 & -1.280 \mathrm{E}-05 & 1.104 \mathrm{E}-05 & 3.305 \mathrm{E}+10 & 1.978 \mathrm{E}+10 & 8.329 \mathrm{E}+09 & 0.296 \\ 43.3 & -1.858 \mathrm{E}-05 & 1.164 \mathrm{E}-05 & 3.614 \mathrm{E}+10 & 2.233 \mathrm{E}+10 & 9.503 \mathrm{E}+09 & 0.296 \\ 48.9 & -4.077 \mathrm{E}-05 & 1.227 \mathrm{E}-05 & 3.923 \mathrm{E}+10 & 2.427 \mathrm{E}+10 & 1.041 \mathrm{E}+10 & 0.296 \\ 54.4 & -6.164 \mathrm{E}-05 & 1.272 \mathrm{E}-05 & 4.231 \mathrm{E}+10 & 2.577 \mathrm{E}+10 & 1.110 \mathrm{E}+10 & 0.296 \\ 60.0 & -7.039 \mathrm{E}-05 & 1.319 \mathrm{E}-05 & 4.539 \mathrm{E}+10 & 2.693 \mathrm{E}+10 & 1.163 \mathrm{E}+10 & 0.296 \\ 65.6 & -7.082 \mathrm{E}-05 & 1.354 \mathrm{E}-05 & 4.848 \mathrm{E}+10 & 2.779 \mathrm{E}+10 & 1.207 \mathrm{E}+10 & 0.296 \\ 71.1 & -6.688 \mathrm{E}-05 & 1.382 \mathrm{E}-05 & 5.213 \mathrm{E}+10 & 2.843 \mathrm{E}+10 & 1.247 \mathrm{E}+10 & 0.296 \\ 76.7 & -6.160 \mathrm{E}-05 & 1.404 \mathrm{E}-05 & 5.577 \mathrm{E}+10 & 2.887 \mathrm{E}+10 & 1.274 \mathrm{E}+10 & 0.296 \\ 82.2 & -5.911 \mathrm{E}-05 & 1.427 \mathrm{E}-05 & 5.728 \mathrm{E}+10 & 2.872 \mathrm{E}+10 & 1.271 \mathrm{E}+10 & 0.296 \\ 87.8 & -5.851 \mathrm{E}-05 & 1.442 \mathrm{E}-05 & 5.667 \mathrm{E}+10 & 2.807 \mathrm{E}+10 & 1.245 \mathrm{E}+10 & 0.296 \\ 93.3 & -5.701 \mathrm{E}-05 & 1.456 \mathrm{E}-05 & 5.606 \mathrm{E}+10 & 2.743 \mathrm{E}+10 & 1.219 \mathrm{E}+10 & 0.296 \\ 98.9 & -5.408 \mathrm{E}-05 & 1.466 \mathrm{E}-05 & 5.709 \mathrm{E}+10 & 2.704 \mathrm{E}+10 & 1.180 \mathrm{E}+10 & 0.296 \\ 104.4 & -5.055 \mathrm{E}-05 & 1.474 \mathrm{E}-05 & 5.812 \mathrm{E}+10 & 2.662 \mathrm{E}+10 & 1.137 \mathrm{E}+10 & 0.296 \\ 110.0 & -4.748 \mathrm{E}-05 & 1.482 \mathrm{E}-05 & 5.913 \mathrm{E}+10 & 2.617 \mathrm{E}+10 & 1.096 \mathrm{E}+10 & 0.296 \\ 115.6 & -4.456 \mathrm{E}-05 & 1.490 \mathrm{E}-05 & 6.015 \mathrm{E}+10 & 2.569 \mathrm{E}+10 & 1.052 \mathrm{E}+10 & 0.296 \\ 121.1 & -4.169 \mathrm{E}-05 & 1.498 \mathrm{E}-05 & 6.118 \mathrm{E}+10 & 2.523 \mathrm{E}+10 & 9.994 \mathrm{E}+09 & 0.296 \\ 126.7 & -3.999 \mathrm{E}-05 & 1.507 \mathrm{E}-05 & 6.092 \mathrm{E}+10 & 2.439 \mathrm{E}+10 & 9.381 \mathrm{E}+09 & 0.296 \\ 132.2 & -3.823 \mathrm{E}-05 & 1.518 \mathrm{E}-05 & 6.065 \mathrm{E}+10 & 2.359 \mathrm{E}+10 & 8.700 \mathrm{E}+09 & 0.296 \\ 137.8 & -3.667 \mathrm{E}-05 & 1.527 \mathrm{E}-05 & 6.037 \mathrm{E}+10 & 2.279 \mathrm{E}+10 & 8.000 \mathrm{E}+09 & 0.296 \\ 143.3 & -3.515 \mathrm{E}-05 & 1.538 \mathrm{E}-05 & 6.011 \mathrm{E}+10 & 2.197 \mathrm{E}+10 & 7.335 \mathrm{E}+09 & 0.296 \\ 148.9 & -3.386 \mathrm{E}-05 & 1.549 \mathrm{E}-05 & 5.985 \mathrm{E}+10 & 2.115 \mathrm{E}+10 & 6.651 \mathrm{E}+09 & 0.296\end{array}$

